\title{
The Chemical Capacitance as a Fingerprint of Defect Chemistry in Mixed Conducting Oxides
}

\author{
Juergen Fleig,* Alexander Schmid, Ghislain M. Rupp, Christoph Slouka, \\ Edvinas Navickas, Lukas Andrejs, Herbert Hutter, Lukas Volgger \\ and Andreas Nenning
}

\author{
Institute of Chemical Technologies and Analytics \\ Vienna University of Technology, Getreidemarkt 9-164/EC, 1060 Vienna, Austria \\ * Corresponding author: E-mail: j.fleig@ tuwien.ac.at \\ phone: 0043158801 15800; fax: 004315880115899
}

Received: 29-01-2011

Didicated to Janko Jamnik

\begin{abstract}
The oxygen stoichiometry of mixed conducting oxides depends on the oxygen chemical potential and thus on the oxygen partial pressure in the gas phase. Also voltages may change the local oxygen stoichiometry and the amount to which such changes take place is quantified by the chemical capacitance of the sample. Impedance spectroscopy can be used to probe this chemical capacitance. Impedance measurements on different oxides $\left((\mathrm{La}, \mathrm{Sr}) \mathrm{FeO} \mathrm{F}_{3-\delta}=\mathrm{LSF}, \mathrm{Sr}(\mathrm{Ti}, \mathrm{Fe}) \mathrm{O}_{3-\delta}=\right.$ $\mathrm{STF}$, and $\left.\mathrm{Pb}(\mathrm{Zr}, \mathrm{Ti}) \mathrm{O}_{3}=\mathrm{PZT}\right)$ are presented, and demonstrate how the chemical capacitance may affect impedance spectra in different types of electrochemical cells. A quantitative analysis of the spectra is based on generalized equivalent circuits developed for mixed conducting oxides by J. Jamnik and J. Maier. It is discussed how defect chemical information can be deduced from the chemical capacitance.
\end{abstract}

Keywords: Defect chemistry, impedance spectroscopy, mixed conductors, chemical capacitance

\section{Introduction}

Many oxides exhibit a significant degree of mixed ion and electron conduction at higher temperatures. Their transport properties are thus usually determined by motion of ionic as well as electronic defects, for example oxygen vacancies and electrons/electron holes. Several mixed conducting oxides such as $\mathrm{Sr}$-doped $\mathrm{LaCoO}_{3}$ or La$\mathrm{FeO}_{3}$ can be employed in cathodes of solid oxide fuel cells. ${ }^{1,2}$ Those materials exhibit high electronic conductivity in air, mostly also at lower temperatures, and substantial ionic conductivity at operation temperatures of several hundred ${ }^{\circ} \mathrm{C}$. However, also in oxides with applications relying on a high insulation resistance at room temperature, mixed conductivity might become relevant either at high temperatures or upon high field load. ${ }^{3-8}$ Examples for such materials are lead zirconate titanate (PZT) in actuators or $\mathrm{BaTiO}_{3}$ in capacitors.

Investigation of the electrical and dielectric properties of mixed conducting oxides is often performed by im- pedance spectroscopy. For a quantitative analysis of the impedance spectra, physical models are required and most models rely on equivalent circuits. Either circuits are simply used to parameterize a spectrum (e.g. two serial RCelements for describing two semicircles in a complex impedance plane), or specific physical models are developed and mapped by equivalent circuits. The latter is often done on a somewhat intuitive basis. For example, the impedance of a mixed conductor with ion blocking and electron conducting electrodes might be represented by two parallel resistors for ion $\left(\mathrm{R}_{\text {ion }}\right)$ and electron $\left(\mathrm{R}_{\text {eon }}\right)$ conduction, the parallel geometrical capacitance of the sample with permittivity $\varepsilon\left(\mathrm{C}_{\text {geo }}\right)$ and a serial capacitance $\mathrm{C}_{\mathrm{el}}$ in the ionic rail, reflecting the ion blocking character of the electrodes (Fig. 1). This circuit is indeed able to describe some of the corresponding experiments but fails in other cases.

The transport equations governing mixed ionic electronic conductors (MIECs) were used in numerous papers by J. R. Macdonald to rigorously calculate the impedance 


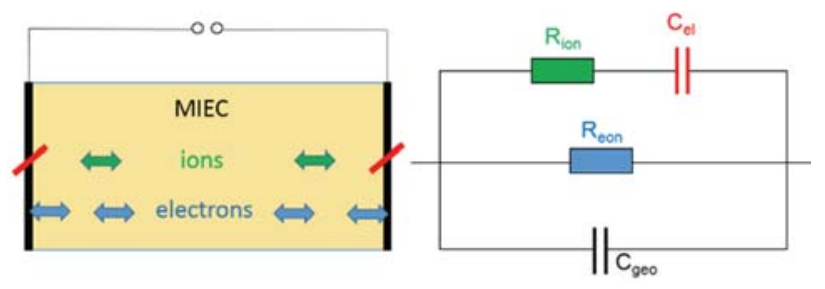

Fig. 1. Sketch of a mixed ionic and electronic conductor (MIEC) with ions blocked at the electrodes and an intuitive (but not exact) equivalent circuit describing such a situation.

of many specific situations. ${ }^{9,10}$ The disadvantage of those numerical calculations, however, is the challenge of intuitively predicting how parameter changes affect spectra shapes and also the difficulty of applying numerical models when quantifying experimental data. Generalized equivalent circuits describing the impedance of mixed conductors were not available until J. Jamnik and J. Maier published several seminal papers on this topic. ${ }^{1-13}$ There, the circuit in Fig. 2a was introduced as the generalized equivalent circuit of a homogeneous mixed conductor. For specific experiments appropriate boundary conditions ha- ve to be considered via terminal circuit elements to take account of processes such as oxygen exchange at a MIEC surface or ion/electron blocking at an electrode.

The essential additional element compared to the intuitive circuit in Fig. 1 is the chemical capacitance $\mathrm{C}_{\text {chem }}$ in its differential version $\left(\mathrm{dC}_{\text {chem }}\right)$. This chemical capacitance couples the ionic and electronic rails of charge transport by allowing local changes of stoichiometry and leads to the transmission line-type character of the circuit. It is a measure of the readiness for stoichiometry changes and describes the electroneutral chemical storage of charges, in contrast to an electrostatic capacitor with charge separation. For the sake of simplicity the geometrical sample capacitance $\mathrm{C}_{\mathrm{geo}}$, which is in parallel to the entire circuit and describes the dielectric displacement current, is not included here.

This chemical capacitance contains important information on the defect chemistry of oxides and is mainly determined by the concentration of the minority charge carrier. In this publication we first specify the theory of the chemical capacitance in mixed conducting oxides and then examples are given, where the measurement of the chemical capacitance is used to reveal information on de-

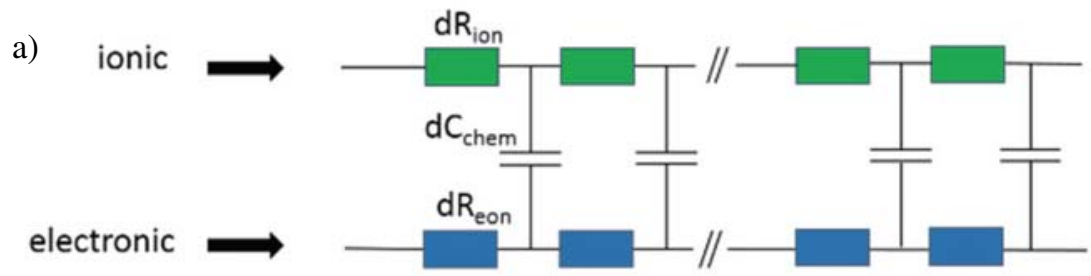

b)

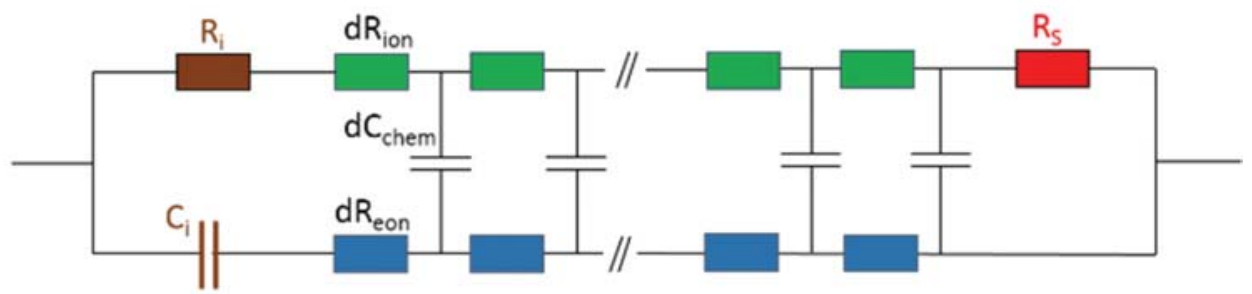

electrolyte

mixed conducting electrode (MIEC)

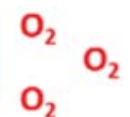

c)

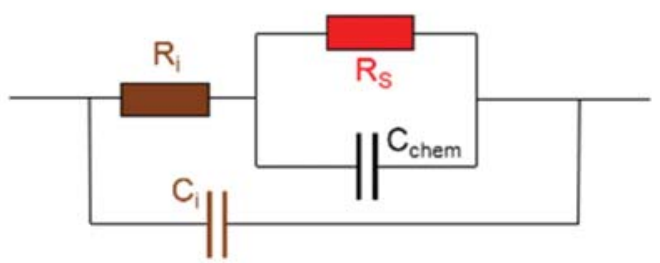

Fig. 2. (a) Transmission line-type equivalent circuit of a mixed conductor with differential chemical capacitances $\mathrm{dC}_{\text {chem }}$ coupling the ionic and the electronic rails of charge transport. The parallel geometrical sample capacitance $\left(\mathrm{C}_{\mathrm{geo}}\right)$ is not included here. (b) The same circuit including terminal elements for a homogeneous mixed conducting electrode in a solid oxide fuel/electrolysis cell with oxygen exchange at the surface (resistor $\mathrm{R}_{\mathrm{S}}$ ), an interfacial charge transfer resistance $\mathrm{R}_{\mathrm{i}}$ and electron blocking at the MIEC/electrolyte interface $\left(\mathrm{C}_{\mathrm{i}}\right)$. (c) Simplified circuit resulting from (b) when neglecting the transport resistances $\mathrm{R}_{\mathrm{ion}}$ and $\mathrm{R}_{\text {eon }}$. 
fect chemical properties of mixed conducting oxides. Moreover, the generalized MIEC equivalent circuit is applied to deconvolute of ionic and electronic contributions to the total conductivity.

\section{The Chemical Capacitance of a Mixed Conducting Oxide}

The chemical capacitance of an oxide ${ }^{12}$ is defined by

$$
\mathrm{C}_{\text {chem }}=4 \mathrm{~F}^{2} \operatorname{Vn}^{0}\left(\frac{\partial \mu_{\mathrm{O}}}{\partial \mathrm{c}_{\mathrm{O}}}\right)^{-1}
$$

In Eq. (1) F is Faraday's constant, V the sample volume. The key factor is the derivative of the oxygen chemical potential $\mu_{\mathrm{O}}$ with respect to the normalized oxygen concentration of oxygen $c_{\mathrm{O}}$; normalization of the concentration is done with respect to the absolute concentration of oxygen sites $\mathrm{n}^{0}$. The normalized oxygen concentration $\mathrm{c}_{\mathrm{O}}$ is directly related to the non-stoichiometry $\delta$ of a metal oxide $\mathrm{MO}_{1-\delta}$. The chemical potential of oxygen in an oxide is given by the chemical potentials of oxide ions and electrons via

$$
\mu_{\mathrm{O}}=\mu_{\mathrm{O}^{2-}}-2 \mu_{\mathrm{e}^{-}} .
$$

In the following we consider an oxide with oxygen vacancies (V) as dominating ionic defects and electronic defects (eon) either as electrons (e) or holes (h); electron or hole traps are neglected. The oxygen chemical potential can then be expressed as

$$
\mu_{\mathrm{o}}=-\mu_{\mathrm{v}}+2 \mathrm{z}_{\text {eon }} \mu_{\text {eon }}
$$

with eon $=\mathrm{e}$ or $\mathrm{h} ; \mathrm{z}_{\text {eon }}$ denotes the charge number of the electronic defect, e.g. -1 for e.

The variation of the oxygen stoichiometry can be described by

$$
\mathrm{dc}_{\mathrm{O}}=-\mathrm{dc}_{\mathrm{v}}
$$

and concentration changes of electronic and ionic defects are coupled by the local electroneutrality, i.e. via

$$
\mathrm{dc}_{\text {eon }}=-2 \mathrm{z}_{\text {eon }} \mathrm{dc}_{\mathrm{V}}=2 \mathrm{z}_{\text {eon }} \mathrm{dc}_{\mathrm{O}} \text {. }
$$

Differentiating Eq. (3) with respect to $\mathrm{c}_{\mathrm{O}}$ and combining with Eqs. (4) and (5) results in

$$
\frac{\partial \mu_{o}}{\partial c_{o}}=-\frac{\partial \mu_{V}}{\partial c_{o}}+2 z_{e o n} \frac{\partial \mu_{e o n}}{\partial c_{O}}=\frac{\partial \mu_{V}}{\partial c_{V}}+4 \frac{\partial \mu_{\text {eon }}}{\partial c_{e o n}} .
$$

In the case of dilute ionic as well as electronic defects, chemical potentials of all defects $d$ can be expressed as

$$
\mu_{\mathrm{d}}=\mu_{\mathrm{d}}^{0}+\mathrm{RT} \ln \mathrm{c}_{\mathrm{d}}
$$

with normalized defect concentrations

$$
\mathrm{c}_{\mathrm{d}}=\frac{\mathrm{n}_{\mathrm{d}}}{\mathrm{n}^{0}} \text {. }
$$

In Eq. (7) $\mu_{d}^{0}$ is the standard chemical potential of the defect. Hence, we find

$$
\frac{d \mu_{d}}{d c_{d}}=\frac{R T}{c_{d}}
$$

and by inserting relation (9) into Eq. (6) we get

$$
\frac{\partial \mu_{\mathrm{o}}}{\partial \mathrm{c}_{\mathrm{o}}}=\mathrm{RT}\left(\frac{1}{\mathrm{c}_{\mathrm{v}}}\right)+4 \mathrm{RT}\left(\frac{1}{\mathrm{c}_{\mathrm{eon}}}\right)
$$

We finally obtain from Eqs. (1) and (10)

$$
\mathrm{C}_{\text {ehem }}=\frac{4 \mathrm{~F}^{2} \mathrm{Vn}^{0}}{\mathrm{RT}} \frac{1}{\left(\frac{1}{\mathrm{c}_{\mathrm{v}}}+\frac{4}{\mathrm{c}_{\text {eon }}}\right)}=\frac{\mathrm{F}^{2} \mathrm{~V}}{\mathrm{RT}} \frac{1}{\left(\frac{1}{4 \mathrm{n}_{\mathrm{v}}}+\frac{1}{\mathrm{n}_{\text {eon }}}\right)} \text {. }
$$

In many cases the concentrations of electronic and ionic defects differ strongly and the chemical capacitance is determined by the minority charge carrier concentration $\left(\mathrm{n}_{\min }\right)$, or, more precisely, by the smaller of the two $\mathrm{z}_{\mathrm{d}}{ }^{2} \mathrm{n}_{\mathrm{d}}$ values $\left(z_{d}=\right.$ charge number of the defect $)$. This results in the simplified relation

$$
C_{\text {chem }} \approx \frac{F^{2} V}{R T} z_{\min }^{2} n_{\min } .
$$

Alternatively, we may also express the chemical capacitance with the so-called thermodynamic factor of oxygen. In general, the thermodynamic factor (f) of particle, defect or component $\mathrm{k}$ is defined by

$$
\mathrm{f}_{\mathrm{k}}=\frac{\partial \ln \mathrm{a}_{\mathrm{k}}}{\partial \ln \mathrm{c}_{\mathrm{k}}} .
$$
via

The activity $a_{k}$ is related to the chemical potential $\mu_{k}$

$$
\mu_{\mathrm{k}}=\mu_{\mathrm{k}}^{0}+\mathrm{RT} \ln \mathrm{a}_{\mathrm{k}}
$$

and the standard chemical potential $\mu_{0}^{\mathrm{k}}$ is constant by definition. Hence, the relation between any chemical potential and oxygen concentration is given by

$$
\frac{\partial \mu_{\mathrm{O}}}{\partial \mathrm{c}_{\mathrm{O}}}=\frac{\partial \mu_{\mathrm{O}}}{\partial \ln \mathrm{c}_{\mathrm{O}}} \frac{\partial \ln \mathrm{c}_{\mathrm{O}}}{\partial \mathrm{c}_{\mathrm{O}}}=\frac{\mathrm{RT}}{\mathrm{c}_{\mathrm{O}}} \frac{\partial \ln \mathrm{a}_{\mathrm{O}}}{\partial \ln \mathrm{c}_{\mathrm{O}}}=\frac{\mathrm{RT}}{\mathrm{c}_{\mathrm{O}}} \mathrm{f}_{\mathrm{O}} .
$$

The chemical capacitance of Eq. (1) is thus given by 


$$
\mathrm{C}_{\text {chem }}=\frac{4 \mathrm{~F}^{2} \mathrm{Vn}}{\mathrm{RT}} \frac{1}{\mathrm{f}_{\mathrm{O}}} \text { with } \mathrm{n}_{\mathrm{O}}=\mathrm{n}^{0} \mathrm{c}_{\mathrm{O}} \text {. }
$$

In case of our mixed conducting oxide, the thermodynamic factor of oxygen $\mathrm{f}_{\mathrm{O}}$ can be calculated by Eqs. (15) and (6), resulting in

$$
f_{O}=\frac{c_{O}}{R T}\left(\frac{\partial \mu_{V}}{\partial c_{V}}+4 \frac{\partial \mu_{e o n}}{\partial c_{e o n}}\right) .
$$

When thermodynamic factors are introduced also for defects $\left(f_{d}\right)$, we get with

$$
\frac{\partial \mu_{d}}{\partial c_{d}}=\frac{\partial \mu_{d}}{\partial \ln c_{d}} \frac{\partial \ln c_{d}}{\partial c_{d}}=R T \frac{\partial \ln a_{d}}{\partial \ln c_{d}} \frac{1}{c_{d}}=\frac{R T}{c_{d}} f_{d}
$$

and Eq. (17) the relation

$$
\mathrm{f}_{\mathrm{O}}=\frac{\mathrm{c}_{\mathrm{O}}}{\mathrm{c}_{\mathrm{v}}} \mathrm{f}_{\mathrm{v}}+4 \frac{\mathrm{c}_{\mathrm{O}}}{\mathrm{c}_{\text {eon }}} \mathrm{f}_{\text {eon }} \text {. }
$$

For diluted defects we have $f_{\text {eon }}=f_{V}=1$ and inserting this thermodynamic factor of oxygen into Eq. (1) again results in Eq. (11). For dilute defects in mixed conducting oxides the thermodynamic factor of oxygen is of the order of the inverse normalized concentration of the minority defect and thus often larger than 100. This simple reason of high $\mathrm{f}_{\mathrm{O}}$ values was already emphasized in Ref. 14 .

\section{Defect Chemistry and Chemical Capacitances of Polarized Fuel Cell Model Electrodes}

Acceptor-doped perovskite type oxides $\left(\mathrm{ABO}_{3}\right)$ are the standard materials for cathodes in solid oxide fuel cells. The (relative negative) dopant charge, e.g. of $\mathrm{Sr}$ on the A-site of $\mathrm{LaBO}_{3}$ is charge balanced either by oxygen vacancies or electron holes. The B-cation strongly affects the amount of oxygen vacancies found at operation temperatures of several hundred ${ }^{\circ} \mathrm{C}$ in synthetic air. However, also the oxygen partial pressure $\mathrm{p}\left(\mathrm{O}_{2}\right)$ plays an important role and lowering $\mathrm{p}\left(\mathrm{O}_{2}\right)$ may strongly increase the oxygen vacancy concentration at the expense of electron holes. This is reflected in so-called Brouwer-diagrams ${ }^{15,16}$ where defect concentrations are plotted versus the oxygen partial pressure, see Fig. 3. As a result of these dependencies, acceptor-doped oxides exhibit high oxygen vacancy concentrations and thus excellent ionic conductivity in reducing atmosphere, but the electronic conductivity might become rather low under such conditions. When using acceptordoped oxides in anodes of solid oxide fuel cells (see e.g. Refs. 17-20), an additional electron conducting phase might thus be very helpful. A systematic study of the properties of model electrodes with metallic current collec-

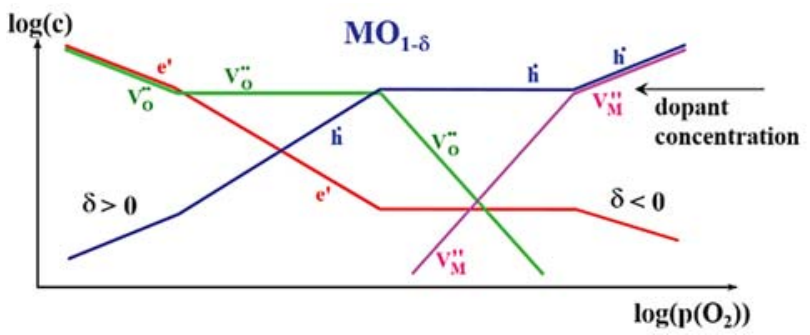

Fig. 3. Sketch of the Brouwer diagram of an acceptor-doped nonstoichiometric oxide $\mathrm{MO}_{1-\delta}$ indicating the partial pressure dependence of all relevant ionic and electronic defects.

tors, based on $\mathrm{Sr}$-doped $\mathrm{LaFeO}_{3}$ and $\mathrm{Fe}$-doped $\mathrm{SrTiO}_{3}$ thin films under reducing conditions can be found in Refs. 21,22 .

When mixed conductors are used as electrodes in solid oxide fuel cells, the MIEC surface terminal of the equivalent circuit in Fig. 2a has to be modeled by a surface resistance $R_{S}$ that describes the oxygen exchange. At the MIEC-electrolyte interface, an additional resistance $\left(\mathrm{R}_{\mathrm{i}}\right)$, representing ion transfer into the electrolyte, is added see Fig. 2b. Moreover, electrons are blocked at the electrode/electrolyte interface, which is taken into account by a capacitor $\mathrm{C}_{\mathrm{i}}$ in the electronic rail. However, in many thin film electrodes ionic as well as electronic charge transport across the film is sufficiently fast to warrant the assumption of negligible $\mathrm{R}_{\text {eon }}$ and $\mathrm{R}_{\text {ion }}$. Hence, only the equivalent circuit shown in Fig. $2 c$ remains from Fig. $2 b$. This very simple model is indeed often applicable to analyze the impedance of mixed conducting thin film electrodes. ${ }^{23}$ It allows to determine the surface-related polarization resistance and the chemical capacitance of the electrode with both $\mathrm{R}_{\mathrm{S}}$ and $\mathrm{C}_{\text {chem }}$ depending on the applied overpotential. The voltage dependence of $R_{S}$ was hardly investigated so far and is difficult to predict due to the lack of information on the atomistic reaction mechanism of oxygen exchange. Voltage dependent chemical capacitances, on the other hand, should reflect the bulk defect chemical changes upon voltage load.

In most model type thin film electrodes, the oxygen exchange reaction at the surface is rate limiting and leads to the largest part of the electrochemical electrode resistance, i.e. $R_{\mathrm{S}} \gg \mathrm{R}_{\mathrm{i}}$. As a consequence, the chemical potential of oxygen $\left(\mu_{\mathrm{O}}\right)$ in the MIEC electrode is directly related to the electrode overpotential via Nernst's equation. Thus, $\mu_{O}$ in the electrode can be modified by an applied voltage in the same manner as by changing the outer gas atmosphere and the $\mathrm{x}$-axis of the Brouwer diagram in Fig. 3 can also be scanned by varying the overpotential of the respective electrode. This similarity of changes caused by voltage or oxygen partial pressure was used, for example, in Ref. 24 to interpret impedance data.

The strong relationship between chemical capacitance and defect chemistry, i.e. the decisive role of the minority charge carrier concentration (Eq. (12)), 
becomes also clear in the following measurement: $\mathrm{La}_{0.6} \mathrm{Sr}_{0.4} \mathrm{FeO}_{3-\delta}$ (LSF) thin films were deposited on yttria stabilized zirconia (YSZ) single crystals and patterned to circular microelectrodes. A low resistance porous LSF/Pt layer was used as counter electrode. To guarantee a homogeneous electrochemical potential of electrons in the thin film electrode even for very low $\mu_{\mathrm{O}}$, a micro-patterned Pt thin film grid was deposited beneath the LSF film (see Fig. 4). Impedance spectra were measured in ambient air for a broad range of bias voltages and always include a large low frequency semicircle in the complex impedance plane (Fig. 4). This arc reflects the polarization resistance due to surface oxygen exchange and the chemical capacitance of the film. Both $\mathrm{R}_{\mathrm{S}}$ and $\mathrm{C}_{\text {chem }}$ depend on the applied voltage.

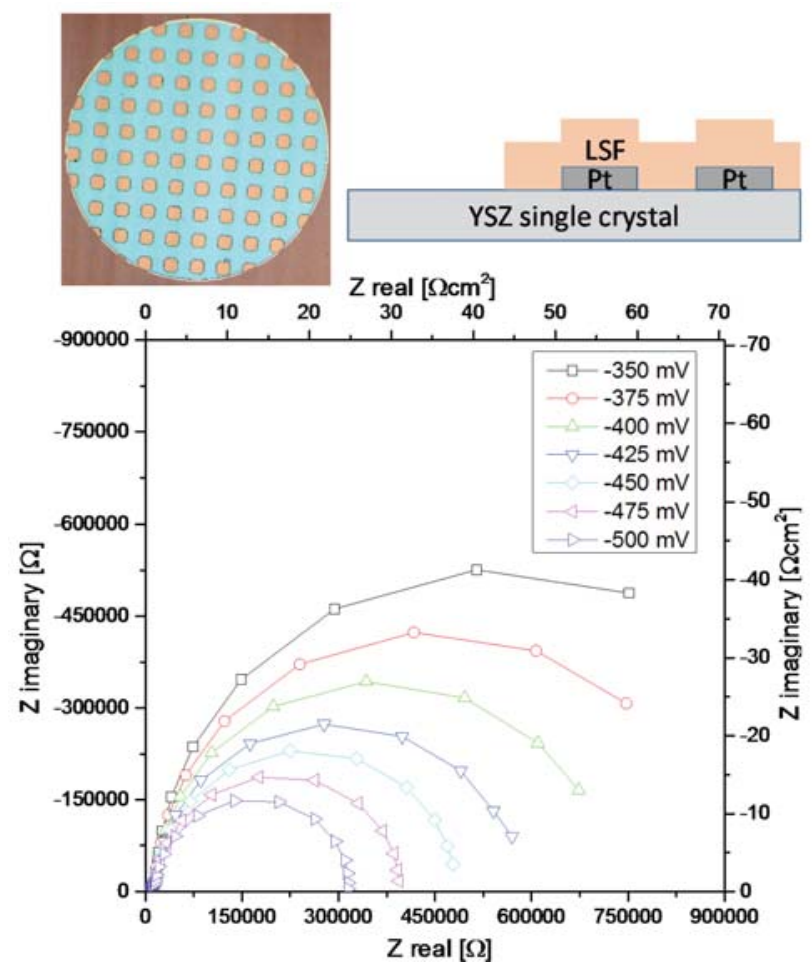

Fig. 4. Impedance spectra measured in air at $600{ }^{\circ} \mathrm{C}$ on circular LSF thin film microelectrodes with Pt grid beneath (the photograph of a microelectrode and a sketch of the cross section is also shown); the microelectrodes were deposited on top of an yttria stabilized zirconia single crystal (porous LSF/Pt counter electrode). Depending on the applied cathodic bias voltage the impedance changes.

Chemical capacitances extracted from the main arc are then normalized to the active volume of the thin film electrode and the electrode overpotentials are related to the oxygen partial pressure by Nernst's equation. The resulting capacitance - partial pressure diagram is shown in Fig. 5. From high to low pressures there is first an increase of $\mathrm{C}_{\text {chem }}$, then a strong decrease by more than one order of magnitude and finally again an increase. Qualitatively, this very characteristic behavior can be easily understood from a)

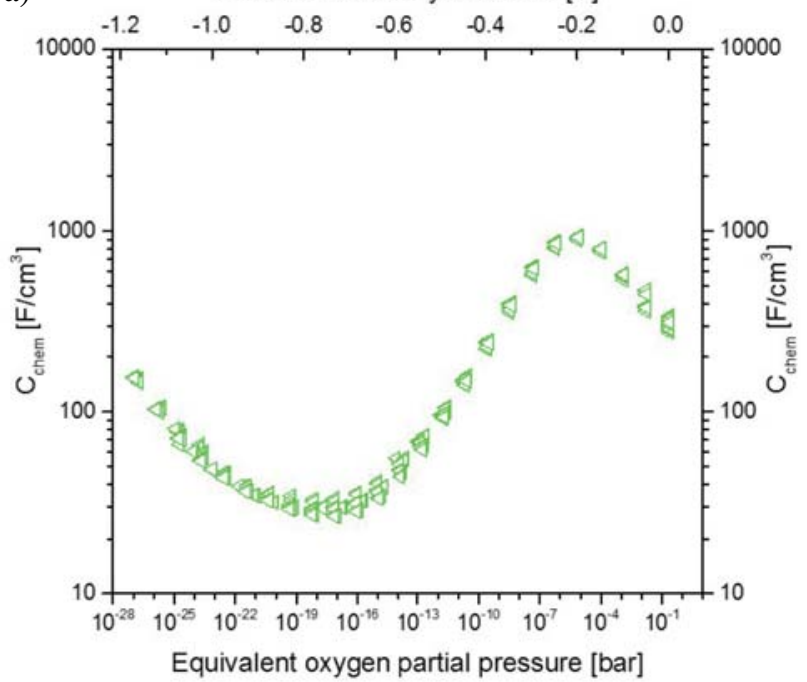

b)

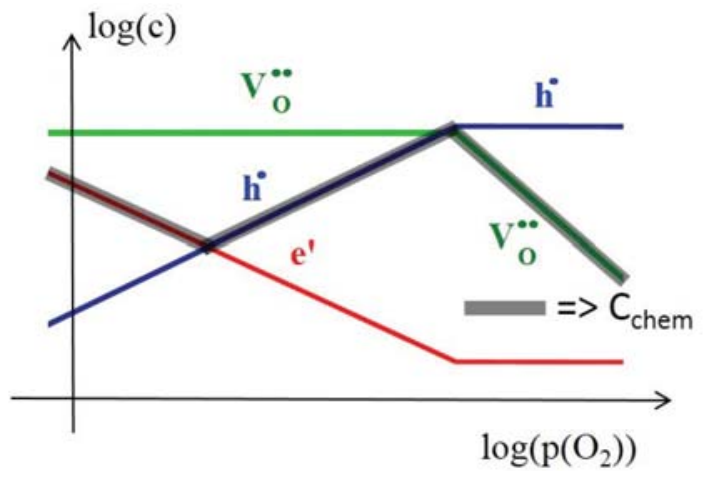

Fig. 5. (a) Chemical capacitances measured at $600{ }^{\circ} \mathrm{C}$ in air in dependence of the electrode overpotential (upper abscissa) and the corresponding $\mathrm{p}\left(\mathrm{O}_{2}\right)$ (bottom abscissa, calculated by Nernst's equation). $\mathrm{C}_{\mathrm{chem}}$ is determined from the main arc of the spectra (cf. Fig. 4) and is normalized to the active electrode volume. (b) Sketch of a part of the Brouwer diagram in Fig. 3, indicating the partial pressure dependence of the minority charge carrier concentration which determines $\mathrm{C}_{\text {chem }}$; the decisive charge carrier is reflected by the grey line in parallel to the concentrations.

the concept of chemical capacitances described above, i.e. from Eq. (12). The chemical capacitance reflects the concentration of the minority charge carrier and for high oxygen partial pressures those are the oxygen vacancies. Their concentration and thus $\mathrm{C}_{\text {chem }}$ increases with decreasing partial pressure until oxygen vacancies become the majority charge carrier counter balancing the $\mathrm{Sr}$ dopant, see the detail of the Brouwer diagram sketched in Fig. 5 b.

Then, holes (often interpreted as $\mathrm{Fe}^{4+}$ ) are in minority, though still exhibiting higher concentrations than electrons $\left(\mathrm{Fe}^{2+}\right)$. In accordance with the Brouwer diagram the hole concentration, i.e. $\mathrm{C}_{\text {chem }}$ decreases with decreasing $\mathrm{p}\left(\mathrm{O}_{2}\right)$ until the intrinsic point of the semiconducting LSF is reached. For even lower $\mathrm{p}\left(\mathrm{O}_{2}\right)$ electrons become more important than holes. Accordingly, the relevant minority charge carrier concentration and thus $\mathrm{C}_{\text {chem }}$ increa- 
ses with decreasing partial pressure, again in accordance with the Brouwer diagram. This clearly shows that the chemical capacitance is indeed an excellent indicator of defect chemical changes in materials. However, it has to be emphasized, that only for dilute situations $\mathrm{C}_{\text {chem }}$ scales linearly with defect concentrations, which is not expected for highly doped LSF. A more detailed analysis of these measurements will be given in a forthcoming paper. A similar analysis of the chemical capacitance, relating defect chemical changes and overpotential as given in Refs. 25,26 for doped ceria.

\section{The Role of the Chemical Capacitance in MIECs with Ion Blocking Electrodes}

Similar to a Warburg impedance, the MIEC equivalent circuit in Fig. 2 is based on a transmission line. However, in contrast to a Warburg impedance it includes finite resistances in both conduction rails. Still, there are situations in which MIEC circuits include ideal Warburg elements. One example may be found for a MIEC with two ion blocking electrodes. Ion blocking is taken into account by the terminating capacitors $\mathrm{C}_{\mathrm{el}}$ in the ionic rail (Fig. 6a). An analytical solution (even including further resistive and capacitive terminating elements in the two rails) is given in Refs. 12 and 27. For chemical capacitances being much larger than the ion blocking capacitor, the analytical expression of the impedance simplifies to

$$
\begin{aligned}
Z= & R_{\text {eon } / / \text { ion }}+\left(R_{\text {eon }}-R_{\text {eon } / / \text { ion }}\right) \\
& \frac{\tanh \left(\sqrt{\frac{i \omega C_{\text {chem }}\left(R_{\text {eon }}+R_{\text {ion }}\right)}{4}}\right)}{\sqrt{i \omega C_{\text {chem }}\left(R_{\text {eon }}+R_{\text {ion }}\right) / 4}} .
\end{aligned}
$$

The first term in Eq. (20), $\mathrm{R}_{\text {eon/ion, }}$, refers to the sample resistance relevant for high frequencies $R_{h f}$ and is a parallel connection of the electronic $\left(\mathrm{R}_{\text {eon }}\right)$ and ionic $\left(\mathrm{R}_{\text {ion }}\right)$ resistance:

$$
R_{h f}=R_{\text {eon } / / \text { ion }}=\left(R_{\text {eon }}{ }^{-1}+R_{\text {ion }}{ }^{-1}\right)^{-1} .
$$

The second term corresponds to the analytical expression of a Warburg impedance with resistance $\mathrm{R}_{\mathrm{W}}$ and fit element $T_{W}$, i.e. to

$$
\mathrm{Z}_{\mathrm{w}}=\mathrm{R}_{\mathrm{w}} \frac{\tanh \left(\sqrt{\mathrm{i} \omega \mathrm{T}_{\mathrm{w}}}\right)}{\sqrt{\mathrm{i} \omega \mathrm{T}_{\mathrm{w}}}}
$$

with

$$
\mathrm{T}_{\mathrm{w}}=\frac{\mathrm{C}_{\text {chem }}\left(\mathrm{R}_{\text {eon }}+\mathrm{R}_{\text {ion }}\right)}{4} .
$$
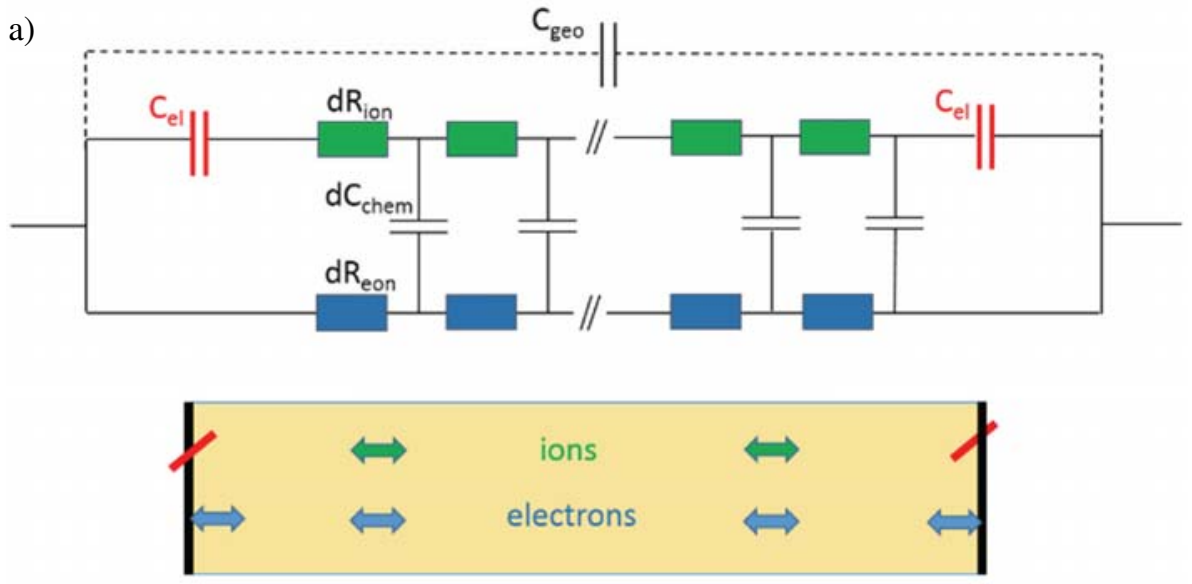

b)

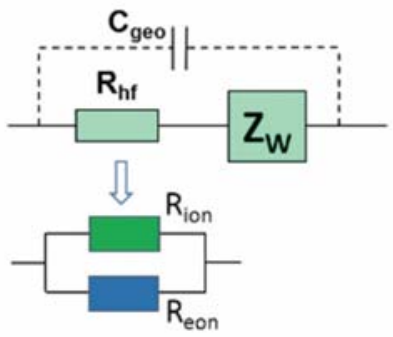

Fig. 6. (a) Equivalent circuit of a mixed conductor (cf. Fig. 2a) with terminals representing ideal ion blocking electrodes with negligible electronic contact resistance, the corresponding situation is sketched beneath. Here, the parallel dielectric displacement current via the geometrical sample capacitance $\mathrm{C}_{\text {geo }}$ is also taken into account. (b) Simplified equivalent circuit valid for $\mathrm{C}_{\text {chem }} \gg \mathrm{C}_{\mathrm{el}} ; \mathrm{Z}_{\mathrm{W}}$ denotes a finite Warburg impedance. The two serial elements $\left(\mathrm{R}_{\mathrm{hf}}\right.$ and $\left.\mathrm{Z}_{\mathrm{W}}\right)$ correctly represent the analytical expression of the impedance but are not serial in real space. 
Thus, the simple model circuit in Fig. $6 \mathrm{~b}$ can be introduced to describe such a situation. Please note that the two elements $R_{h f}=R_{\text {ion/leon }}$ and $Z_{W}$ do no longer represent two serial processes in real space; both include ionic as well as electronic resistances in the entire sample. Still, the corresponding impedance spectra should exhibit the typical shape of a Warburg impedance with $45^{\circ}$ slope at high frequencies and semicircle-like shape at low frequencies. Indeed, such spectra can be measured and an example can be found in Ref. 28 for silver telluride.

Here, we show results obtained from $300 \mathrm{~nm}$ thin films of $\mathrm{SrTi}_{0.3} \mathrm{Fe}_{0.7} \mathrm{O}_{3-\delta}$ (STF) prepared by pulsed laser deposition on a $\mathrm{MgO}$ substrate. STF is a promising mixed conductor for application in SOFC cathodes ${ }^{29}$ and anodes,${ }^{20}$ defect chemical properties were extensively investigated in Ref. 30. In our study, interdigital Pt finger electrodes were deposited on top of these films (see Fig. 7 top) and the impedance was measured in reducing atmosphere $\left.\left(\mathrm{p}\left(\mathrm{H}_{2}\right) / \mathrm{p}\left(\mathrm{H}_{2} \mathrm{O}\right)\right)=1\right)$ at ca. $650^{\circ} \mathrm{C}$. The resulting impedance spectrum is indeed characterized by a resistive high frequency intercept and a Warburg-type impedance, see Fig. 7 bottom, including fit line. The high frequency intercept reflects the total conductivity of the thin film since at such high frequencies both ions and electrons can move $\left(\mathrm{R}_{\text {eon/ion }}\right)$; ion blocking is not relevant. At very low frequencies, however, ions are blocked at the electrodes and only electrons contribute. When neglecting additional non-idealities such as an interfacial resistance also for electrons or the two dimensionality of the current lines due to the electrode geometry, the total DC resistance therefore represents the electronic resistance and can be used to calculate the electronic conductivity $\sigma_{\text {eon }}$. In this specific case $\sigma_{\text {eon }}=0.037 \mathrm{~S} / \mathrm{cm}$ results at ca. $700{ }^{\circ} \mathrm{C}$
The diameter of the Warburg type impedance indicates, how much the additional (parallel) ion conduction can lower the overall resistance; its resistance $R_{W}$ does not simply correspond to the ionic or electronic resistance or the "ionic minus electronic resistance" but is given by

$$
\mathrm{R}_{\mathrm{W}}=\mathrm{R}_{\text {eon }}-\mathrm{R}_{\text {eon } / \text { ion }}=\frac{\mathrm{R}_{\text {eon }}^{2}}{\mathrm{R}_{\text {eon }}+\mathrm{R}_{\text {ion }}} .
$$

From the resistive fit parameters of the circuit in Fig. $6 b$, i.e. from the high frequency intercept $R_{h f}$ and $R_{w}$, the ionic resistance can therefore be calculated as

$$
R_{\text {ion }}=\frac{\left(R_{h f}+R_{w}\right) R_{h f}}{R_{W}}=R_{\text {con }} \frac{R_{h f}}{R_{W}} .
$$

Here we obtain an ionic conductivity of $0.021 \mathrm{~S} / \mathrm{cm}$ at ca. $650{ }^{\circ} \mathrm{C}$ in reducing atmosphere, which is only slightly lower than the electronic conductivity.

The result of a similar experiment on slightly $\mathrm{Nd}$ donor-doped lead zirconate titanate (PZT) with a composition close to the morphotropic phase boundary is shown in Fig. 8a. The impedance was measured between Agcontaining inner electrodes of a PZT multilayer stack (Fig. 8b) consisting of $80 \mu \mathrm{m}$ PZT layers. Above ca. 600 ${ }^{\circ} \mathrm{C}$ a second feature appears at low frequencies of the impedance spectrum that again resembles a Warburg impedance. An example, measured at $707^{\circ} \mathrm{C}$, is shown in Fig. $8 \mathrm{a}$, together with a fit of the measurement data to the circuit in Fig. 6b (after subtracting an inductive contribution due to wiring). Essentially, the same interpretation as for the STF thin films is possible: At low frequencies only electrons contribute to charge transport $\left(\mathrm{R}_{\mathrm{eon}}\right)$ while at

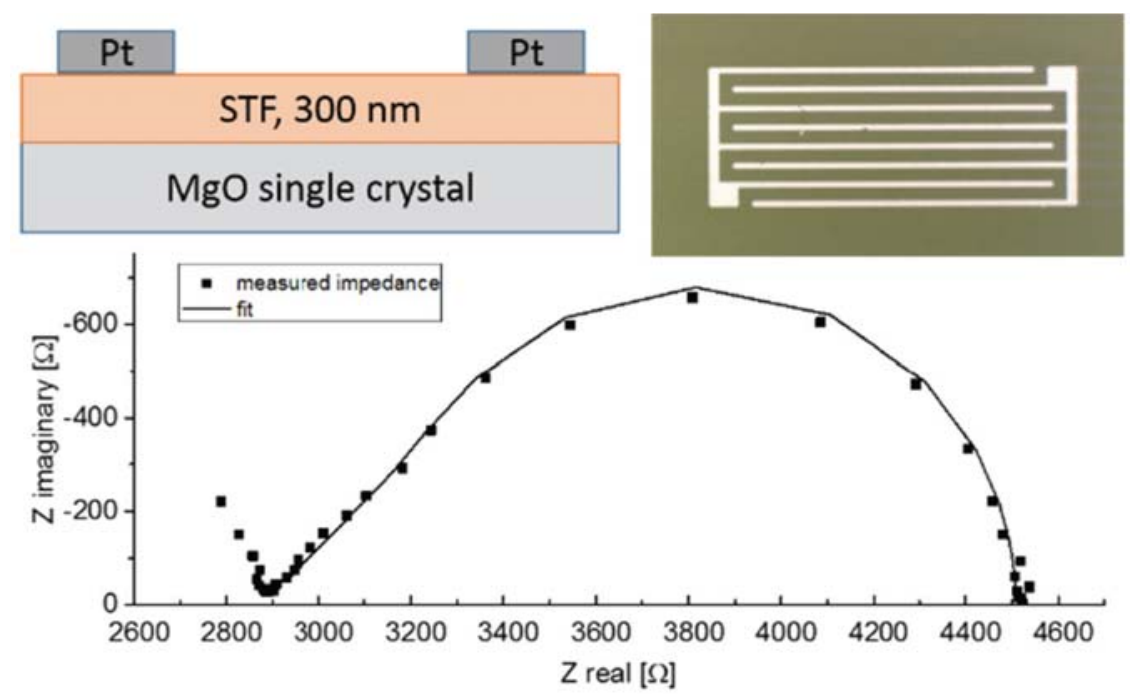

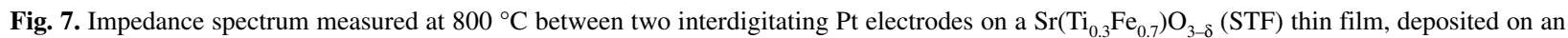
insulating $\mathrm{MgO}$ substrate (sketch); the photograph shows a top view of the electrode geometry. The spectrum can be fitted to the circuit in Fig. $6 \mathrm{c}$ with a rather ideal finite Warburg element at low frequencies. 


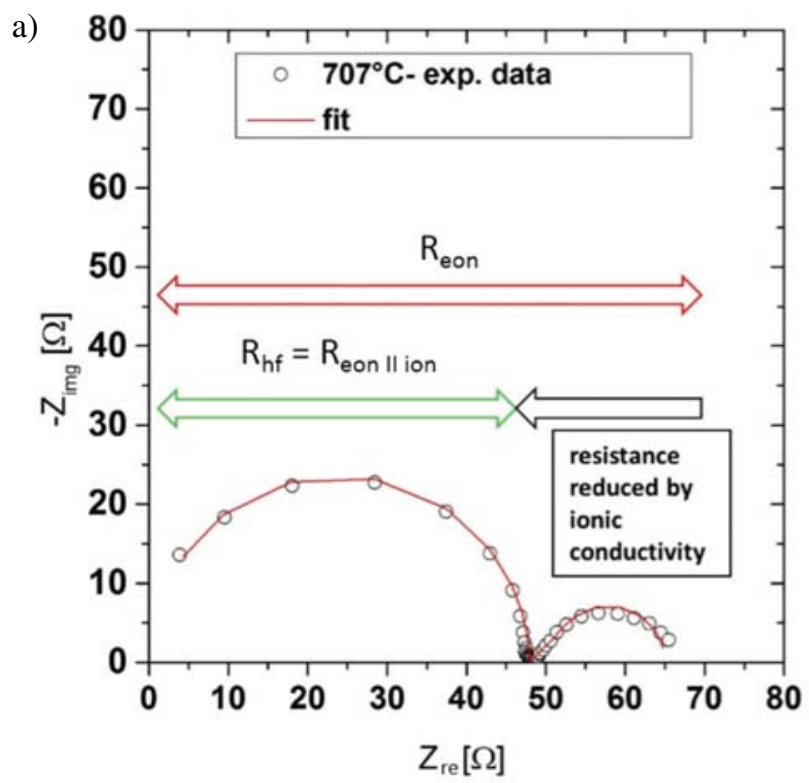

b)
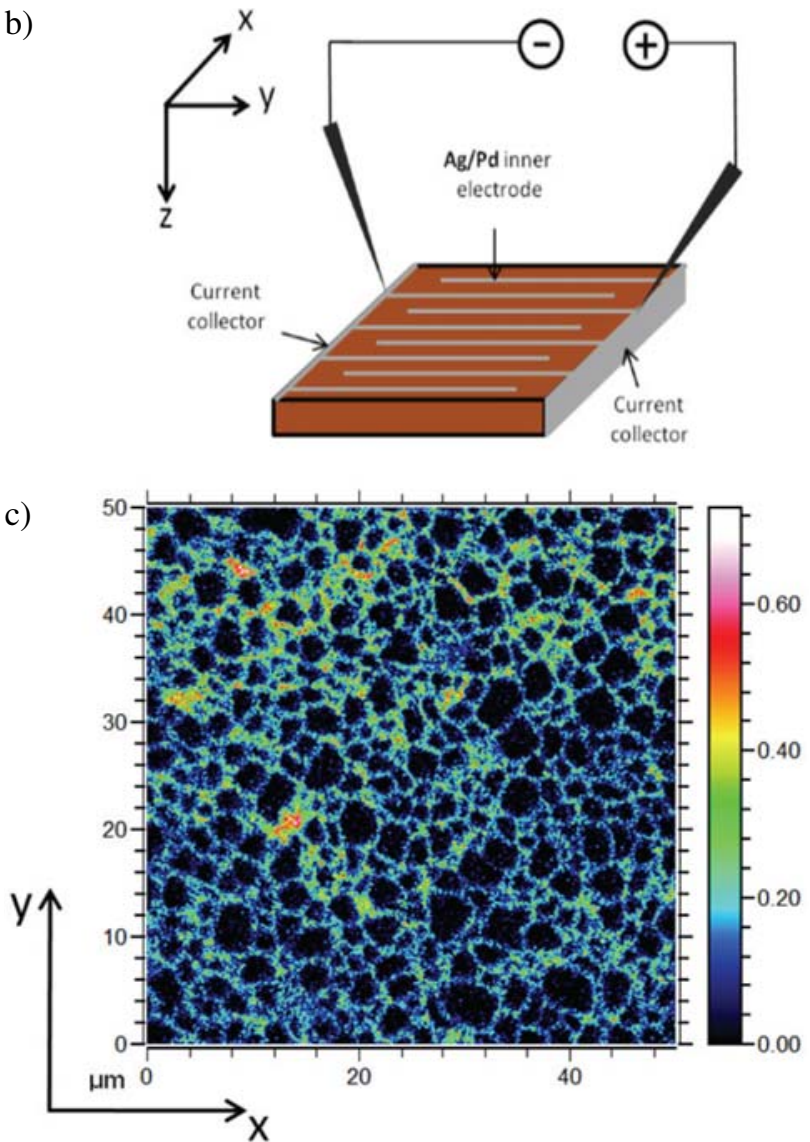

Fig. 8. (a) Impedance spectrum of a PZT multilayer stack piece with interdigitating $\mathrm{Ag} / \mathrm{Pd}$ electrodes, measured at $707^{\circ} \mathrm{C}$ and corrected for wiring inductance. A fit to the simplified circuit in Fig. $6 \mathrm{~b}$ is also shown. The arrows indicate the meaning of the arcs (diameters) in terms of resistances. (b) Sketch of the sample geometry. (c) ${ }^{18} \mathrm{O}$ distribution image of a PZT polycrystal after exposure to ${ }^{18} \mathrm{O}_{2}$ at $676{ }^{\circ} \mathrm{C}$ for 30 minutes, measured by SIMS. High ${ }^{18} \mathrm{O}$ concentrations at grain boundaries clearly indicate that ion transport is mainly along grain boundaries.

high frequencies ions and electrons can move, leading to the lower $\mathrm{R}_{\mathrm{hf}}$ resistance. Again the resistances can be used to calculate ionic and electronic conductivities and we obtain $1.6^{*} 10^{-5} \mathrm{~S} / \mathrm{cm}$ for ions and $4.6^{*} 10^{-5} \mathrm{~S} / \mathrm{cm}$ for electrons at $707^{\circ} \mathrm{C}$.

In this specific case, a significant ionic conductivity is somewhat surprising since donor dopants are usually assumed to suppress oxygen vacancy formation. Here, the analysis of the chemical capacitance comes into play. According to Eqs. (23) and (24) the chemical capacitance can be determined from the fit parameter $\mathrm{T}_{\mathrm{w}}$ and the ionic and electronic resistances:

$$
C_{\text {chem }}=\frac{4 T_{W}}{R_{\text {eon }}+R_{\text {ion }}}=\frac{4 T_{w} R_{w}}{\left(R_{h f}+R_{w}\right)^{2}} .
$$

Assuming oxygen vacancies as minority charge carriers, we can use Eq. (26) and $\mathrm{C}_{\text {chem }}=4 \mathrm{n}_{\mathrm{v}} \mathrm{F}^{2} \mathrm{~V} / \mathrm{RT}$ from Eq. (12) to determine the oxygen vacancy concentration. A value of about $10 \mathrm{ppm}$ with respect to oxygen sites in PZT results for the given measurement data. This value is unusually high for a (nominally) donor-do- ped material and may come from $\mathrm{PbO}$ evaporation during sintering, which turns a nominally donor doped PZT into a slightly acceptor doped PZT with hole conduction. ${ }^{31}$

However, here another effect comes into play: Oxygen tracer diffusion measurements with subsequent secondary ion mass spectrometry (SIMS) analysis revealed that the ionic transport and thus the majority of oxygen vacancies is located in or close to grain boundaries (Fig. 8c). When normalizing the measured "effective" ionic conductivity to a grain boundary width of ca. $2 \mathrm{~nm}$ we find impressively high oxide ion conductivities along grain boundaries in the range of $10^{-2} \mathrm{~S} / \mathrm{cm}$ at ca. $700{ }^{\circ} \mathrm{C}$. This is already within the order of magnitude of the best oxide ion conductors. The exact mechanism leading to such a high interfacial ionic conductivity is still under discussion, but there is indication that an accumulation of oxygen vacancies in a space charge layer plays a major role. This also means that most probably the largest contribution to the chemical capacitance comes from this region. More details on these effects can be found in Ref. 32. 


\section{Conclusions}

Two different types of solid state electrochemical cells were shown in which chemical capacitances play an important role. First, the capacitance of mixed conducting thin film electrodes on oxide ion conductors is often a chemical capacitance, while the main resistance is caused by the oxygen exchange reaction at the surface. By applying a voltage, the oxygen chemical potential in the electrode can be varied. Measuring the bias dependent chemical capacitance thus reveals information on the minority charge carrier concentrations. In LSF, three different regimes could be identified with different minority charge carriers dominating the chemical capacitance (oxygen vacancies, holes and electrons, respectively). Second, spectra measured on mixed conducting oxides with ion blocking electrodes may yield Warburg type features in impedance spectra, which again include information on the chemical capacitance. For STF thin films and PZT samples, this type of measurement was used to separate ionic and electronic conductivities. For PZT, the chemical capacitance also allowed an estimate of the oxygen vacancy concentration present despite donor doping. The corresponding ionic conductivity, however, is largely carried by grain boundaries, as shown by oxygen tracer exchange experiments.

\section{Acknowledgement}

Financial support of the Austrian Science Fund (FWF), projects F4509-N16 and W1243-N16)) as well as of the Christian-Doppler Research Association (CDG), Christian Doppler Laboratory of Ferroic Materials is acknowledged. The authors further thank Elizabeth Miller and Scott Barnett, Northwestern University, Evanston, for supplying the STF target

\section{References}

1. S. B. Adler, Chemical Reviews 2004; 104; 4791-4843. http://dx.doi.org/10.1021/cr020724o

2. T. Kawada, H. Yokokawa, Key Engineering Materials 1997; 125-126; 187-248. http://dx.doi.org/10.4028/www.scientific.net/KEM.125-126.187

3. R. Waser, T. Baiatu, K.-H. Haerdtl, J. Am. Ceram. Soc. 1990; $73 ; 1645-1653$. http://dx.doi.org/10.1111/j.1151-2916.1990.tb09809.x

4. R. Waser, T. Baiatu, K.-H. Haerdtl, J. Am. Ceram. Soc. 1990; 73; 1654-1662. http://dx.doi.org/10.1111/j.1151-2916.1990.tb09810.x

5. S. Rodewald, J. Fleig, J. Maier, J. Europ. Ceram. Soc. 1999; 19; 797-801. http://dx.doi.org/10.1016/S0955-2219(98)00317-3

6. S. Rodewald, N. Sakai, K. Yamaji, H. Yokokawa, J. Fleig, J. Maier, J. Electroceram. 2001, 7, 95-105.
7. I. Denk, W. Munch, J. Maier, J. Am. Ceram. Soc. 1995, 78, 3265-3672. http://dx.doi.org/10.1111/j.1151-2916.1995.tb07963.x

8. F. Noll, W. Munch, I. Denk, J. Maier, Solid State Ionics 1996, 86-88, 711-717. http://dx.doi.org/10.1016/0167-2738(96)00155-5

9. J. R. Macdonald, Electrochimica Acta 1992, 37, 1007-1014. http://dx.doi.org/10.1016/0013-4686(92)85216-8

10. J. R. Macdonald, D. R. Franceschetti, J. Chem. Phys. 1978, 68, 1614-1637. http://dx.doi.org/10.1063/1.435929

11. J. Jamnik, J. Maier, S. Pejovnik, Electrochimica Acta 1999, 44, 4139-4145.

http://dx.doi.org/10.1016/S0013-4686(99)00128-0

12. J. Jamnik, J. Maier, J. Electrochem. Soc. 1999, 146, 41834188. http://dx.doi.org/10.1149/1.1392611

13. J. Jamnik, J. Maier, Phys. Chem. Chem. Phys. 2001, 3, 1668-1678. http://dx.doi.org/10.1039/b100180i

14. J. Maier, J. Am. Ceram. Soc. 1993, 76, 1212-1217. http://dx.doi.org/10.1111/j.1151-2916.1993.tb03743.x

15. G. Brouwer, Philips Research Reports 1954, 9, 366-376.

16. F. W. Poulsen, Solid State Ionics 2000, 129,145-162. http://dx.doi.org/10.1016/S0167-2738(99)00322-7

17. C. Sun, U. Stimming, Journal of Power Sources 2007, 171, 247-260. http://dx.doi.org/10.1016/j.jpowsour.2007.06.086

18. S. W. Tao, J. T .S. Irvine, Nat. Mater. 2003, 2, 320-323. http://dx.doi.org/10.1038/nmat871

19. D. E. Fowler, J. M. Haag, C. Boland, D. M. Bierschenk, S. A. Barnett, K. R. Poeppelmeier, Chem. Mat. 2014, 26, 31133120. http://dx.doi.org/10.1021/cm500423n

20. S. Cho, D. E. Fowler, E. C. Miller, J. S. Cronin, K.R. Poeppelmeier, S. A. Barnett, Energy Environ. Sci. 2013, 6, 18501857. http://dx.doi.org/10.1039/c3ee23791e

21. S. Kogler, A. Nenning, G. M. Rupp, A. K. Opitz, J. Fleig, J. Electrochem. Soc. 2015, 162, F317-F326. http://dx.doi.org/10.1149/2.0731503jes

22. A. Nenning, A. K. Opitz, T. M. Huber, J. Fleig, Phys. Chem. Chem. Phys. 2014, 16, 22321-22336. http://dx.doi.org/10.1039/C4CP02467B

23. F. S. Baumann, J. Fleig, H. U. Habermeier, J. Maier, Solid State Ionics 2006, 177, 1071-1081. http://dx.doi.org/10.1016/j.ssi.2006.02.045

24. T. Kawada, J. Suzuki, M. Sase, A. Kaimai, K. Yashiro, Y. Nigara, J. Mizusaki, K. Kawamura, H. Yugami, J. Electrochem. Soc. 2002, 149, E252-E259. http://dx.doi.org/10.1149/1.1479728

25. D. Chen, S. R. Bishop, H. L. Tuller, Chem. Mat. 2014, 26, 6622-6628. http://dx.doi.org/10.1021/cm503440v

26. D. Chen, H. L. Tuller, Advanced Functional Materials 2014, 24, 7638-7644. http://dx.doi.org/10.1002/adfm.201402050

27. W. Lai, S. M. Haile, J. Am. Ceram. Soc. 2005, 88, 29792997. http://dx.doi.org/10.1111/j.1551-2916.2005.00740.x

28. R. Andreaus, W. Sitte, J. Electrochem. Soc. 1997, 144, 10401044. http://dx.doi.org/10.1149/1.1837527

29. W. Jung, H. L. Tuller, Solid State Ionics 2009, 180, 843-847. http://dx.doi.org/10.1016/j.ssi.2009.02.008 
30. A. Rothschild, W. Menesklou, H. L. Tuller, E. Ivers-Tiffee, Chem. Mat. 2006, 18, 3651-3659. http://dx.doi.org/10.1021/cm052803x

31. C. Slouka, L. Andrejs, J. Fleig, J. Electroceram. 2014, 33,
221-229. http://dx.doi.org/10.1007/s10832-014-9954-9

32. C. Slouka, G. Holzlechner, L. Andrejs, E. Navickas, H. Hutter, J. Fleig, J. Am. Ceram. Soc. 2015, 98, 3259-3269. http://dx.doi.org/10.1111/jace.13769

\section{Povzetek}

Ker je stehiometrija kisika v mešanih prevodnih oksidih odvisna od kemijskega potenciala kisika, je zato pomemben kisikov parcialen tlak v plinski fazi. Prav tako lahko različne električne napetosti spremenijo lokalno stehiometrijo kisika in intenzivnost pri kateri se take spremembe dogajajo. Spremembe lahko kvantificiramo s kemijsko kapacitivnostjo vzorca, ki jo izmerimo z impedančna spektroskopija. V članku so predstavljene impedančne meritve različnih oksidov $\left((\mathrm{La}, \mathrm{Sr}) \mathrm{FeO}_{3-\delta}=\mathrm{LSF}, \mathrm{Sr}(\mathrm{Ti}, \mathrm{Fe}) \mathrm{O}_{3-\delta}=\mathrm{STF}\right.$, and $\left.\mathrm{Pb}(\mathrm{Zr}, \mathrm{Ti}) \mathrm{O}_{3}=\mathrm{PZT}\right)$. Prav tako je na teh materialih pokazano, kako lahko kemijska kapacitivnost vpliva na impedančne spektre različnih elektrokemijskih celic. Kvantitativna analiza spektra temelji na generaliziranih ekvivalentnih vezjih. Za mešane prevodne okside, sta jih razvila J. Jamnik in J. Maier. Opisano je tudi, kako lahko defekt kemijske informacije izpeljemo iz kemijske kapacitivnosti. 